\title{
Nothofagus pumilio forest affected by recent tephra deposition in northern Patagonia. II- Shifts in diversity and structure of rhizosphere fungal communities
}

\author{
Natalia V. Fernández ${ }^{1,2}$, Sonia B. Fontenla ${ }^{1}$, Denise Moguilevsky ${ }^{1,2}$, Sebastian Meier ${ }^{3,5}$, \\ Joaquín Rilling ${ }^{4}$, Pablo Cornejo ${ }^{5,6^{*}}$
}

${ }^{1}$ Laboratorio de Microbiología Aplicada y Biotecnología, Centro Regional Universitario Bariloche, Universidad Nacional del Comahue - IPATEC, Quintral 1250, Bariloche, Argentina. ${ }^{2}$ Consejo Nacional de Investigaciones Cientificas y Técnicas (CONICET), Argentina. ${ }^{3}$ Instituto de Investigaciones Agropecuarias, INIA, CRI Carillanca, Km 10 Camino Cajón-Vilcún, Araucanía, Chile. ${ }^{4}$ Laboratorio de Ecología Microbiana Aplicada, Departamento de Ciencias Químicas y Recursos Naturales, Universidad de La Frontera, Temuco, Chile. ${ }^{5}$ Centro de Investigación en Micorrizas y Sustentabilidad Agroambiental, CIMYSA, Facultad de Ingeniería y Ciencias, Universidad de La Frontera, Temuco, Chile. ${ }^{6}$ Scientific and Technological Bioresource Nucleus, BIOREN-UFRO, Universidad de La Frontera, Temuco, Chile. *Corresponding author: pablo.cornejo@ufrontera.cl

\begin{abstract}
Volcanic eruptions have a significant effect on ecosystems, including soil and its fungal communities. Due to the eruption of the Puyehue-Cordón Caulle in 2011, thick tephra deposits accumulated in several Nothofagus pumilio forests in Northern Patagonia. The tephra deposition affected plant establishment and development during the post-eruption period. In this work we analyzed rhizosphere fungal communities associated with $N$. pumilio seedlings at three study sites sampled three years after the eruption, two with a thick tephra layer $(50 \mathrm{~cm})$ and a third site with no tephra deposition. Denaturing gradient gel electrophoresis (DGGE) was performed for the different fungal communities (Ascomycetes, Basidiomycetes and Total fungi). We found clear shifts in rhizosphere fungal communities, especially for Basidiomycetes and Total fungi. Site-related characteristics, such as type of substrate, light intensity and the existence of understory and previous mycelial networks, seemed to be the main factors determining the structure of these fungal communities. Given their sensitivity to different types of environmental change, these microbial communities could be used as bioindicators. Specifically, Basidiomycetes and total fungi seem to be better bioindicators of environmental changes than ascomycetes. The results shown here contribute to the understanding of how fungal communities respond to disturbance, an important issue in the evaluation of how ecosystem processes might be affected in areas commonly subjected to geological risks, such as volcanism. This information is also relevant to the planning and successful implementation of restoration activities based on seedling optimization by rhizosphere fungi.
\end{abstract}

Keywords: DGGE, Nothofagus pumilio, Puyehue-Cordón Caulle volcanic complex, Pyroclastic material, Rhizosphere fungal communities. 


\section{Introduction}

It is well known that disturbance events generate changes in ecosystem processes and thus determine changes in community structure. Disturbed landscapes therefore provide an opportunity for the study of ecological processes important to ecosystem dynamics and the management of natural resources. This is particularly true of physical disturbance, such as forest fires, floods and storms (Shade et al., 2012; Choi et al., 2017). Volcanic eruptions are also highmagnitude physical disturbances in which lava, tephra and various gases are usually expelled into the atmosphere, tephra fall being one of the major disturbances associated with these events (Swanson and Major, 2005; González et al., 2014). Volcanic eruptions usually have a very serious impact on the structure and dynamics of ecosystems, affecting not only plant and animal communities (Swanson and Major, 2005; González et al., 2014; Swanson et al., 2016), but also microorganisms that have important ecological roles to play (Nara et al., 2003; Yamanaka and Okabe, 2006). Since microbial communities are crucial to the functioning of all ecosystems, understanding the main factors affecting their dynamics is important for prediction of a community's response to disturbance (Shade et al., 2012).

In a related work, the authors described how different abiotic factors, such as light intensity and $\mathrm{P}$ availability, significantly influenced the recruitment and development of Nothofagus pumilio seedlings in native forests severely affected by tephra deposits from the latest eruption of the Puyehue-Cordón Caulle volcanic complex (PCCVC) in 2011. In addition to the abiotic factors evaluated in the above study, several biotic factors, such as soil microorganisms, may also influence $N$. pumilio adaptation to post-eruption conditions. Soil fungi are the dominant eukaryotic lineage in terms of biomass, and play fundamental eco- logical roles as decomposers, mutualists and pathogens, thus contributing to the regulation of aboveground biodiversity (Dighton et al., 2005; Wagg et al., 2011). In addition, fungi are excellent bioindicators of environmental health, including soil quality and fertility (Rai and Varma, 2011). Consequently, in terms of research these organisms represent one of the most interesting microbial groups in the soil environment. The fact that in Patagonia several studies are being carried out on mycorrhizas (Fontenla et al., 1998; Fernández et al., 2012; Nouhra et al., 2013; Fernández et al., 2015; Marín et al., 2016) and other soil fungal communities (Mestre et al., 2011; 2014; 2017; Díaz et al., 2017) reinforces the importance of describing these organisms in natural ecosystems. However, shifts in fungal communities after drastic volcanic eruption has not been previously studied, despite being quite a frequent natural disturbance in this region. In the first years following the PCCVC eruption, seed germination occurred directly on the thick tephra deposits; therefore, roots were not able to exploit the underlying soil. Since nutrient content in the tephra may not be sufficiently rich to satisfy vegetation requirements (Cremona et al., 2011), the fungal communities associated with the root systems of $N$. pumilio seedlings might be a decisive factor in determining recruitment of individuals and development of the forest, as has been described for other plant species in different ecosystems (Nara and Hogetsu, 2004; Allen et al., 2005).

Over the last two decades, methods used to describe the diversity of soil microbial communities have shifted from cultivation-based to culture-independent approaches, which is of critical importance to the understanding of soil ecology, since only a minor fraction of soil microbial communities is cultivable $(\sim 1 \%)$. Some widely used molecular methods are 
fingerprinting techniques, which provide a profile of the genetic diversity in a microbial community. Denaturing gradient gel electrophoresis (DGGE) is one of the most commonly used methods for typing and comparing soil microbial communities. Using DGGE many samples can be analyzed simultaneously, making this technique a powerful tool for monitoring community behavior after environmental change (Muyzer et al., 2004; Valášková and Baldrian, 2009). The result of DGGE is a pattern of bands, the number of which corresponds to the number of predominant members in the microbial community, and band intensities indicate their relative abundance. This molecular method also has some limitations; for example, a single band may not necessarily represent one species alone, since different DNA sequences with identical GC contents may have similar motilities. Taking this into account, it should be considered that the "picture" of communities provided by DGGE fingerprinting is mostly related to the structure and relative abundance of the main populations, rather than to total richness and diversity (Muyzer and Smalla, 1998; Muyzer et al., 2004; Valášková and Baldrian, 2009).

Based on the above, the aim of this study was to analyze different fungal communities associated with the rhizosphere of $N$. pumilio seedlings almost three years after the PCCVC eruption in two sites with large tephra deposits ( $\sim 50 \mathrm{~cm})$, and to compare them with rhizosphere communities of seedlings growing in a forest minimally affected by tephra deposition $(0-2 \mathrm{~cm})$. DGGE was used to study the different fungal communities (Ascomycetes, Basidiomycetes and Total fungi). We tested the hypothesis that the structure of rhizosphere fungal communities associated with $N$. pumilio roots was similar for seedlings growing on the thick tephra deposits, but significantly different from those of seedlings established in the forest soil.

\section{Material and Methods}

\subsection{Study area and sampling}

This study was carried out in native N. pumilio forests of Northern Patagonia, the sampling sites being located on the border between Argentina and Chile. Briefly, two study sites were located close to the international border crossing, connecting Argentina and Chile (Cardenal Samoré), where the tephra layer is approximately $50 \mathrm{~cm}$ in depth. At one of the sites most of the adult trees survived the tephra fall (Cardenal Samoré $1=\mathrm{CS} 1$ ), while at the other a high proportion of trees died as a consequence of the volcanic eruption (Cardenal Samoré $2=\mathrm{CS} 2$ ). The third site was situated at Cerro Otto (CO), where the effect of the eruption was minimal and there was no tephra layer on the soil. In April 2014 (three years after the last PCCVC eruption) five 18-month-old seedlings were collected at each site. Seedlings were carefully removed from the substrate in order to preserve their root systems and the surrounding substrate: i.e., tephra at both Cardenal Samoré sites (CS1 and CS2) and soil on Cerro Otto (CO). All the seedlings were wrapped in individual plastic bags, transported to the laboratory and processed over the following $24 \mathrm{~h}$.

\subsection{Molecular procedures}

The substrate adhered to the roots of each seedling was carefully removed by gentle shaking, air-dried under aseptic conditions, kept in sterile plastic bags and stored at $-80{ }^{\circ} \mathrm{C}$ until their use for molecular analyses. The PowerSoil ${ }^{\circledR}$ DNA Isolation Kit (MOBIO Laboratories) was used for DNA extraction from 0.5 $\mathrm{g}$ of the rhizosphere substrate, according to the manufacturer's specifications. Nested PCRs were used for amplification of the ITS1 region of nuclear rDNA. In the first PCR reaction three pairs of primers were used 
to analyze different groups of fungi: ITS1F / ITS4A, ITS1F / ITS4B and ITS1F / ITS4 for Ascomycetes, Basidiomycetes and Total fungi, respectively (Table 1). For the second PCR reaction the ITS1F / ITS2CG primers (Table 1) were used. Including a GC rich sequence (so called GC-clamp) on one of the primers (ITS2) significantly increases resolution of the band patterns obtained in the DGGE (Muyzer and Smalla, 1998; Valášková and Baldrian, 2009). All PCRs were performed in a total volume of $25 \mu \mathrm{L}$ containing: $\mathrm{ul}$ tra-pure water, $0.5 \mu \mathrm{M}$ of each primer and $1 \times$ GoTaq ${ }^{\circledR}$ qPCR Master Mix (Promega). In the first PCRs, $1 \mu \mathrm{L}$ of the DNA extraction was used as a template, while in the second reaction $0.5 \mu \mathrm{L}$ of the PCR products from the first reaction were used as template DNA. The PCR program used for all the reactions consisted of initial denaturation at $94{ }^{\circ} \mathrm{C}$ for $5 \mathrm{~min}$, followed by 35 cycles of denaturation at $94{ }^{\circ} \mathrm{C}$ for $1 \mathrm{~min}$, annealing at $50{ }^{\circ} \mathrm{C}$ for $1 \mathrm{~min}$, extension at $72{ }^{\circ} \mathrm{C}$ for $1 \mathrm{~min}$, and a final extension at $72{ }^{\circ} \mathrm{C}$ for $10 \mathrm{~min}$. All PCR products were analyzed by electrophoresis in $1 \%$ agarose gels in 1x TAE buffer for $60 \mathrm{~min}$ at $100 \mathrm{~V}$, and stained with GelRedTM nucleic acid gel stain (Biotium Inc.) before DGGE analyses.

PCR products were analyzed by DGGE using a DCode system (Bio-Rad Laboratories, Inc.). Three gels were made, and all samples corresponding to the same group of fungi (Ascomycetes, Basidiomycetes or Total fungi) were included on the same gel for direct comparison of band patterns. Twenty $\mu \mathrm{L}$ of PCR products were loaded onto $6 \%(\mathrm{w} / \mathrm{v})$ polyacrylamide gels with a 40-65\% denaturing gradient (7 M urea and $40 \% \mathrm{v} / \mathrm{v}$ formamide). Electrophoresis was performed in $0.5 \mathrm{x}$ TAE for $12 \mathrm{~h}$ at $100 \mathrm{~V}$. After electrophoresis the gels were stained with SYBR Gold (Molecular Probes, Invitrogen Co.) for $30 \mathrm{~min}$ and then photographed with a UV transilluminator. Following gel staining, the number of bands on the gel was considered an indication of the genetic diversity of the sample (Muyzer et al., 2004).

Table 1. Sequences and references for the primers used in PCR amplifications.

\begin{tabular}{lll}
\hline Primer & SequenCe (5' To 3') & REFERENCE \\
\hline ITS1F & CTTGGTCATTTAGAGGAACTAA & Gardes and Bruns (1993) \\
ITS4 & TCCTCCGCTTATTGATATGC & White et al. (1990) \\
ITS4A & CGCCGTTACTGGGGCAATCCCTG & Larena et al. (1999) \\
ITS4B & CAGGAGACTTGTACACGGTCCAG & Gardes and Bruns (1993) \\
ITS2 & GCTGCGTTCTTCATCGATGC & White et al. (1990) \\
GC-clamp & CGCCCGCCGCGCCCCGCGCCCGTCCCGCCGCCC & Muyzer et al. (1993) \\
& CCGCCCG & \\
\hline
\end{tabular}




\subsection{Diversity indices and statistics}

Clustering of DGGE banding profiles was performed following visualization and quantification of dominant bands using Phoretix 1D analysis software (TotalLab Ltd.). Based on the matrix obtained from this analysis, changes in the presence/absence and abundance of fungal groups were analyzed by non-metric multidimensional scaling (nMDS) using the Primer 6 software (Quest Research Ltd.) and the Bray-Curtis similarity index. Fungal diversity was estimated for each sample using the Simpson (D) and Shannon $\left(\mathrm{H}^{\prime}\right)$ indices (Jorquera et al. 2014). One-way ANOVA followed by Duncan post-hoc tests were used to compare diversity indices obtained from the DGGE analyses $\left(\mathrm{D}\right.$ and $\left.\mathrm{H}^{\prime}\right)$. Finally, a Principal Component Analysis (PCA) was performed, including the different fungal indices calculated in this work, together with some morphological and environmental traits. Statistical analyses were carried out using the IBM SPSS software v. 23.0 (IBM Corp.) and in all cases statistical significance of $\mathrm{p}<0.05$ was considered.

\section{Results}

The DGGE analyses of rhizosphere fungal communities associated with roots of $N$. pumilio seedlings showed different, contrasting situations For Ascomycetes (Figure. 1a) three clusters were mainly observed. One of these included samples corresponding exclusively to seedlings growing in the tephra (Cluster II), while the other cluster samples obtained from the tephra were grouped together with those from the forest soil (Clusters I and III). According to the Bray-Curtis index, the highest similarity values for Ascomycetes corresponded to fungal communities associated with seedlings growing in the tephra (60-70\%), the remaining samples being quite different from each other.
In the case of Basidiomycetes, samples were classified into four distinct clusters (Figure 1b). Clusters I, II and III grouped, almost exclusively, samples corresponding to the rhizosphere of seedlings growing in the tephra (CS1 and CS2), except for one sample from Cerro Otto which was included in Cluster III (CO.4). Cluster IV comprised only samples corresponding to seedlings growing in the forest soil (CO). The BrayCurtis index indicated that the fungal communities of seedlings growing in the tephra were highly similar (60-80\%), while those corresponding to seedlings located in the forest soil (CO) were different from these (CS1 and CS2), and also from each other (the highest similarity value registered for soil samples was $40 \%$ ). For Total fungi (Figure 1c) two main clusters were defined (Clusters I and II), each corresponding to one of the two sites with high tephra deposition located in Cardenal Samoré (Cluster I for CS2 and Cluster II for $\mathrm{CS} 1)$. In addition, these clusters were grouped together and separated from all the forest soil (CO) samples, indicating the clear separation of rhizosphere fungal communities of seedlings present in this environment from those present in the tephra. According to the Bray-Curtis similarity index, rhizosphere fungal communities associated with $N$. pumilio seedling roots located in CS2 were highly similar (60-80\%) and more comparable to the other Cardenal Samoré samples (CS1, $40 \%$ ) than to those from Cerro Otto (CO). As previously observed, most of the forest soil samples were quite different from each other.

The Simpson (D) and Shannon ( $\left.\mathrm{H}^{\prime}\right)$ diversity indices did not vary significantly between sampling sites for any of the fungal groups analyzed (Table 2). According to the factorial analysis performed by means of principal component (PCA) extraction, the first two principal components explained $61 \%$ of the total variance. The different positions of the diversity indices in the multivariate space were mainly related to $\mathrm{pH}$ and conductivity for Basidiomycetes, and to 
bulk density and light intensity for Ascomycetes and Total fungi. In addition, it can be seen that Ascomy cetes and Total fungi were closely related to each other (Figure 2).

a
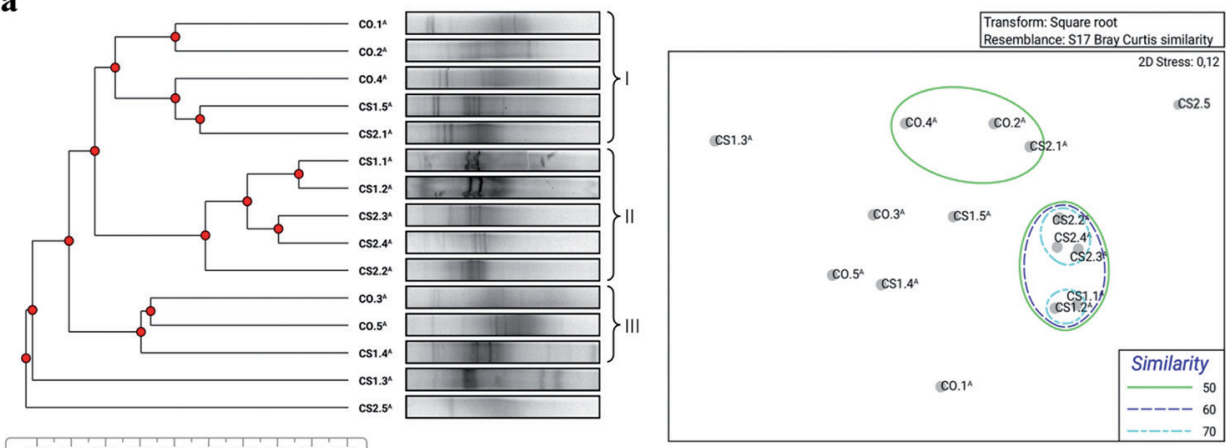

$\begin{array}{lllllllllllllll}0.10 & 0.20 & 0.30 & 0.40 & 0.50 & 0.60 & 0.70 & 0.80 & 0.90 & 1.00\end{array}$

b

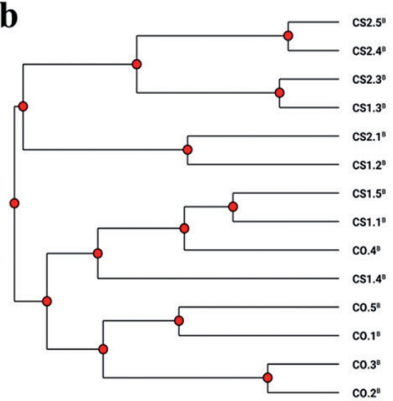

$\begin{array}{llllllllllll}0.10 & 0.20 & 0.30 & 0.40 & 0.50 & 0.60 & 0.70 & 0.80 & 0.90 & 1.00\end{array}$
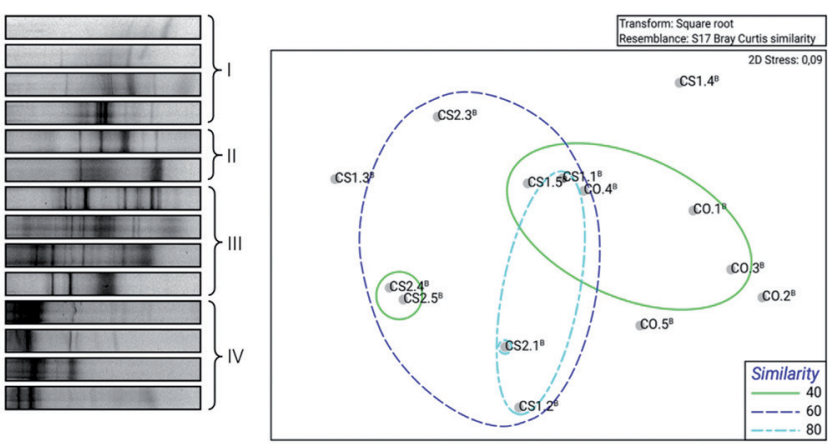

c
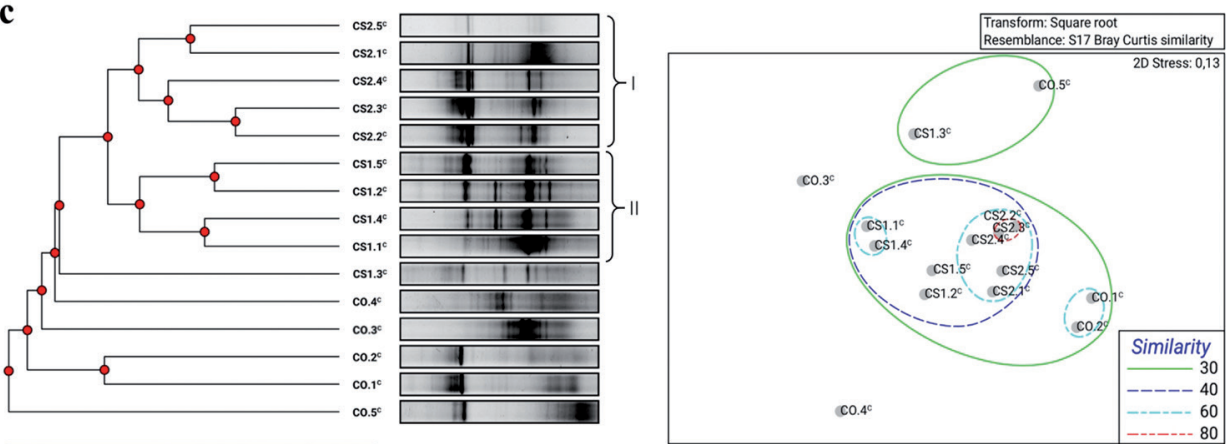

Figure 1. Dendrograms and non-metric multidimensional scaling analyses (nMDS) corresponding to the DGGE profiles obtained for Acomycetes (a), Basidiomycetes (b) and Total fungi (c) associated with the root systems of Nothofagus pumilio seedlings growing in tephra $(\mathrm{CS} 1=$ Cardenal Samoré 1, CS2 = Cardenal Samoré 2$)$ and in forest soil $(\mathrm{CO}=$ Cerro Otto $)$. 
Table 2. Simpson (D) and Shannon $\left(\mathrm{H}^{\prime}\right)$ diversity indices obtained from DGGE analyses for different fungal communities associated with the rhizosphere of Nothofagus pumilio seedlings at sampling sites with thick tephra deposits (Cardenal Samoré 1 and 2) and at the Control site (Cerro Otto).

\begin{tabular}{|c|c|c|c|c|}
\hline \multirow{2}{*}{$\begin{array}{l}\text { DIVERSITY } \\
\text { INDEX }\end{array}$} & \multirow[t]{2}{*}{ SiTE } & \multicolumn{3}{|c|}{ FUNGAL GROUP } \\
\hline & & Ascomycetes & Basidiomycetes & Total fungi \\
\hline \multirow[t]{3}{*}{$D$} & Cardenal Samore 1 & $0.61 \pm 0.07^{\mathrm{a}}$ & $0.70 \pm 0.09^{\mathrm{a}}$ & $0.87 \pm 0.01^{\mathrm{a}}$ \\
\hline & Cardenal Samore 2 & $0.70 \pm 0.05^{\mathrm{a}}$ & $0.73 \pm 0.03^{a}$ & $0.85 \pm 0.01^{\mathrm{a}}$ \\
\hline & Cerro Otto & $0.59 \pm 0.07^{\mathrm{a}}$ & $0.78 \pm 0.03^{\mathrm{a}}$ & $0.77 \pm 0.05^{\mathrm{a}}$ \\
\hline \multirow[t]{3}{*}{$H^{\prime}$} & Cardenal Samore 1 & $0.71 \pm 0.04^{\mathrm{a}}$ & $1.44 \pm 0.30^{\mathrm{a}}$ & $0.98 \pm 0.06^{\mathrm{a}}$ \\
\hline & Cardenal Samore 2 & $0.77 \pm 0.03^{\mathrm{a}}$ & $1.40 \pm 0.10^{\mathrm{a}}$ & $0.92 \pm 0.04^{\mathrm{a}}$ \\
\hline & Cerro Otto & $0.67 \pm 0.09^{\mathrm{a}}$ & $1.62 \pm 0.15^{\mathrm{a}}$ & $0.84 \pm 0.09^{a}$ \\
\hline
\end{tabular}

Values are expressed as mean \pm S.E. Different superscript letters denote significant statistical differences for each fungal group between the three sampling sites.

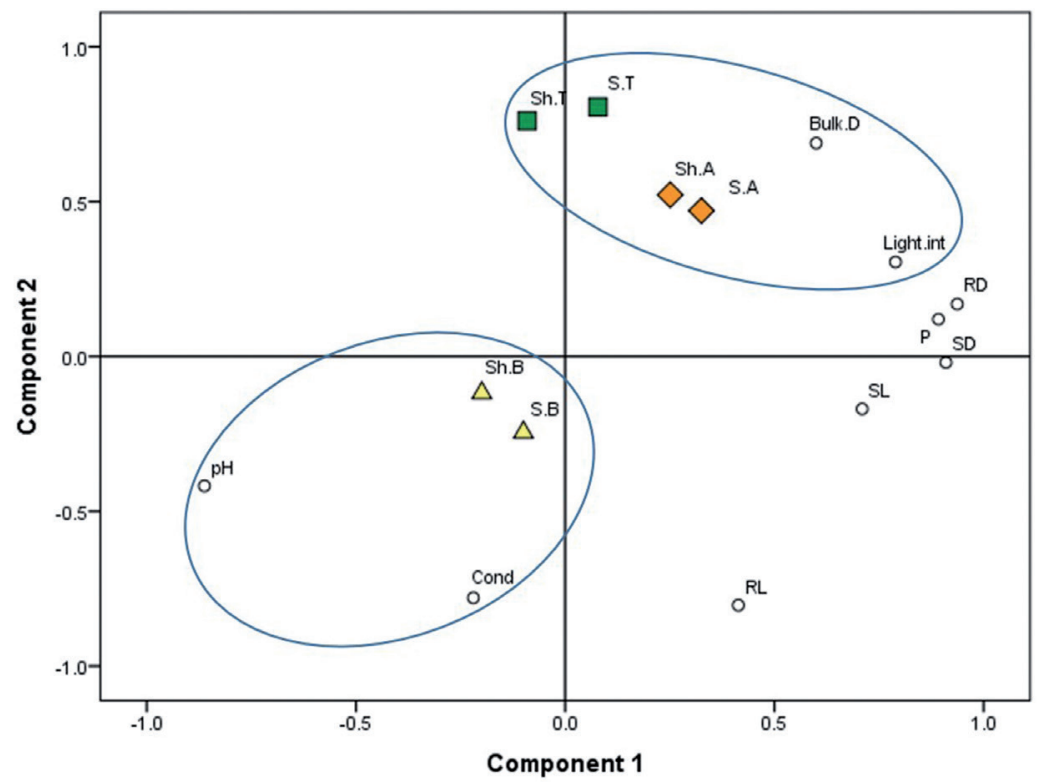

Figure 2. Principal component analysis (PCA) of the different fungal indices calculated in this work for Nothofagus pumilio seedlings, together with some morphological and environmental traits (Shannon and Simpson indices for Ascomycota, Basidiomycota and Total fungi: Sh.A and S.A, Sh.B and S.B, Sh.T and S.T, respectively; SL, RL: shoot and root length, respectively; SD, RD: shoot and root diameter, respectively; P: available phosphorous; Bulk.D: bulk density; Cond: conductivity: Light.int: light intensity). 


\section{Discussion}

Our results from the DGGE analyses showed that variation between the different rhizosphere fungal communities depended mainly on the substrate (tephra or native forest soil) and forest site. Significant differences between substrates or sampling sites were not found for Ascomycetes (Figure 1a). However, in the case of Basidiomycetes a clear separation was observed with respect to the substrate in which the seedlings were growing (Figure 1b). For this group of fungi, rhizosphere fungal communities of the seedlings growing in the forest soil of Cerro Otto (CO) were mostly grouped together and separated from those of the seedlings growing in the tephra (CS1 and CS2), but samples from Cardenal Samoré were not separated into the two different sampling sites even though they had significant environmental differences. Considering that all Nothofagus species worldwide are extensively colonized by ectomycorhizas (EcM), most of which are Basidiomycetes (Tedersoo et al., 2009, Nouhra et al., 2013, Fernández et al., 2015), and that this symbiosis had been registered in N. pumilio seedlings growing in the tephra, this phenomenon could be attributed to the composition of ectomycorrhizal communities, which would be similar in seedlings growing in tephra (CS1 and CS2) but completely different in those located in native forest soil (CO). This is because a volcanic eruption creates a vast barren desert for primary succession due to the recently deposited tephra, where there are very few or no initial fungal propagules, (Nara et al., 2003; Allen et al., 2005; Yamanaka and Okabe 2006), while in the forest soil there are mature and well-established microbial communities and functional mycorrhizal networks.

Regarding Total fungal communities (Figure 1c), differences were detected at both substrate and site levels. We observed that these rhizosphere fungal communities were more similar within each sampling site than between sites, but samples corresponding to seedlings growing in tephra were grouped together and separated from those located in forest soil. The differentiation found between the three sampling sites is most probably related to intrinsic environmental characteristics (eg. light intensity, $\mathrm{pH}$ and $\mathrm{P}$ availability), which ultimately influence microbial communities. For example, the type of substrate (soil), the presence of a dense understory and of well-established mycorrhizal networks clearly differentiate the forest of Cerro Otto (CO) from both sites located in Cardenal Samoré (CS1 and CS2). On the other hand, the clear separation of the DGGE patterns corresponding to the two sites with tephra (CS1 and CS2) might be related to the significant differences in light intensity and available $\mathrm{P}$ registered. These factors directly affect plant growth and photosynthesis rates, influencing nutrient translocation to the rhizosphere and secretion of root exudates (Chang et al., 2002), consequently affecting associated fungal communities.

The results presented here agree with previous studies in forests affected by catastrophic events. For instance, Sun et al. (2015) studied fungal communities across a 152-year forest fire chronosequence and observed that their structure and function were clearly siterelated. Additionally, Yang et al. (1998) showed that the composition of EcM in Larix kaempferi seedlings becoming established during the revegetation process following a volcanic eruption in Japan was affected by elevation, litter accumulation, pumice particle size, and tephra thickness. Yamanaka and Okabe (2006) described the distribution of EcM, bacteria and Frankia in newly deposited tephra and its underlying soil through cultivation of Alnus sieboldiana seedlings in these different substrates, and they also found significant differences in microbial communities present in each substrate (tephra vs. soil). It is important to mention that in addition to environmental factors, intrinsic plant characteristics may also influence rhizosphere 
microbial communities. Nara et al. (2003) demonstrated the underground primary succession pattern of EcM fungi in a volcanic desert on Mt. Fuji in terms of fungal sere, species richness, relative abundance, and community structure, and most results indicate that these successional patterns were closely related to host growth (evaluated as small, middle-sized and large specimens). These findings are in agreement with our results, since the bigger size of seedlings from the site with thick tephra deposits and mostly dead trees (CS2) might also explain the differences in total fungi communities observed between the two sites with tephra (CS1 and CS2).

For the three fungal groups analyzed in this study, the highest similarity values (Bray-Curtis index) were registered for rhizosphere fungal communities of seedlings growing in the tephra (Figure1), thus supporting our initial hypothesis. The structure of rhizosphere fungal communities in $N$. pumilio seedlings were more similar between the two sites with high tephra deposition (CS1 and CS2) than between any of these sites and the forest minimally affected by the eruption (CO). In addition, we observed that DGGE patterns of the seedlings from Cerro Otto (CO) tended to be different not only from those growing in the tephra but also from each other, suggesting that rhizosphere fungal communities were more different and diverse in this environment than at the sites with tephra.

Even though we detected differences in fungal community structure and composition, diversity indices for the different fungal groups (Ascomycota, Basidiomycota, Total fungi) were similar for the three sampling sites (Table 2). Similar results were obtained by Choi et al. (2017), who demonstrated that despite significant changes in both taxonomic composition and functional gene profiles of the soil biota during a microcosm experiment affected by a severe nonselective disturbance, the Shannon diversity index did not show significant changes over time. This phenomenon might be related to the fact that recently disturbed sites have the same (Maaß et al., 2014), or even higher, diversity than stable systems (Maaß et al., 2014; Sun et al., 2015), mainly due to the occurrence of high macro- and micro-scale heterogeneity (Jumpponen and EgertonWarburton, 2005; Iodarche et al., 2009). For example, Sun et al. (2015) found that fungal richness and diversity was higher in a recently burned forest than in sites with more distant fire events. However, some interesting tendencies were evidenced by means of PCA (Figure 2). Firstly, we noticed that the diversity indices estimated in this work seemed to be mostly explained by environmental factors (such as substrate physicochemical characteristics and light intensity) rather than by plant traits (shoot and root length and diameter). Additionally, diversity indices corresponding to Ascomycetes and Total fungi were closely related, suggesting that in the environments studied, the diversity of Ascomycetes may explain much of the diversity of Total fungi. Further studies are needed to explain the tendencies observed, and to relate this information to plant development and ecosystem succession processes.

Altogether, this information indicates that environmental factors (e.g., light intensity and physicochemical characteristics of the substrate) as well as plant traits (e.g., shoot and root length and diameter) directly influence the rhizosphere fungal communities of $N$. pumilio seedlings during its natural regeneration on thick tephra deposits after a volcanic eruption. Similarly, Chapman et al. (2017) suggested that ecosystem structure, largely driven by changes in edaphic and plant community characteristics, strongly influenced microbial function in disturbed and undisturbed permafrost bogs. In the same way, Fernández (2012) used Temperature Gradient Gel Electrophoresis (TGGE) to evaluate changes in different rhizosphere fungal communities (Ascomycetes, Basidiomycetes and Total fungi) of nursery-cultivated individuals of 
$N$. nervosa specimens established under native forest and Pinus plantations. This author also found a significant microbial shift in the fungal communities present in each environment, Basidiomycete richness being significantly higher in the native forest, while Ascomycete richness was higher in the Pinus plantation. Fernández (2012) attributed this difference to the disturbance caused by establishment of a monoculture of an exotic forestry species that significantly altered soil characteristics and previously existing plant communities. The fact that different fungal communities (Ascomycetes, Basidiomycetes, Total fungi) respond differently to the influence of abiotic and biotic factors highlights the potential application of these microbial communities as bioindicators for the study of environmental change and ecological succession. According to our results, in native Nothofagus forests Basidiomycetes and Total fungi seem to be better bioindicators than Ascomycetes, since Basidiomycetes clearly differentiated rhizosphere fungal communities between substrates (soil vs. tephra) and Total fungi distinguished the three sampling sites (CS1, CS2 vs. $\mathrm{CO})$. However, it is important that further studies be carried out in order to describe the fungal species present in the rhizosphere of $N$. pumilio seedlings, their ecological function and how they change over time during the post-eruption period. This would be important not only from an ecological perspective, but also to improve natural or assisted ecological restoration after volcanic eruptions, through the use of adapted fungal isolates able to form ectomycorrhizas under these particular circumstances.

\section{Conclusions}

We found that DGGE analysis of rhizosphere fungal communities of $N$. pumilio seedlings constitutes an interesting molecular tool for describing microbial shifts during succession after high magnitude distur- bances. This points to the possibility of using these fungal communities as bioindicators of environmental change. In this case study we found that Basidiomycetes and Total fungi communities seem to be better bioindicators than Ascomycetes. The changes observed in the different rhizosphere fungal groups with regard to the substrate and sites in which the seedlings were growing could be explained by a combination of several biotic (e.g., plant traits and development, mycorrhiza occurrence) and abiotic factors (e.g., light, $\mathrm{pH}$, water and nutrient content of the substrate). According to our results, these factors influence fungal communities in different ways; for example, site-related characteristics were significant in determining the structure of Total fungi communities, but the type of substrate and probably the EcM associated with the seedlings were more important in structuring Basidiomecete communities. Further study of these dynamic systems is necessary in order to identify how these factors determine different ecological patterns associated with high magnitude disturbances, not only for prediction of how microbial communities respond to disturbance and how this could affect ecosystem processes, but this information could also be used in the development of subsequent assisted restoration activities.

\section{Acknowledgements}

We are grateful to Mr. Jorge Puga and Lic. Pablo Albear for collaborating in sampling and we thank $\mathrm{Na}-$ tional Park Administration for giving us permission to work in a protected area (Permission $\mathrm{N}^{\circ} 1280 / 17$ ). We also thank BSc. (Hons) Audrey Urquhart for language revision. Financial support for this work was provided by grants: PICT2014-1459 (FONCyT), and by the binational Project $\mathrm{CH} / 13 / 01$ (MINCyT, Argentina) - PCCI130008 (CONICYT, Chile). 


\section{References}

Allen, M. F., Crisafulli, C. M., Morris, S. J., EgertonWarburton, L. M., MacMahon, J. A., Trappe, J. M. 2005. Mycorrhizae and Mount St. Helens: story of a symbiosis. In: V. H. Dale, C. M. Swanson, C. M. Crisafulli (eds). Ecological responses to the 1980 eruption of Mt. St. Helens. Springer-Verlag, USA, pp: 221-232.

Chang, A. C., Page, A. L., Koo, B. J. 2002. Biogeochemistry of phosphorus, iron, and trace elements in soils as influenced by soil-plant-microbial interactions. Dev. Soil Sci. 28, 43-57.

Chapman, E. J., Cadillo-Quiroz, H., Childers, D. L., Turetsky, M. R., Waldrop, M. P. 2017. Soil microbial community composition is correlated to soil carbon processing along a boreal wetland formation gradient. Eur. J. Soil Biol. 82, 17-26.

Choi, S., Song, H., Tripathi, B. M., Kerfahi, D., Kim, H., Adams, J. M. 2017. Effect of experimental soil disturbance and recovery on structure and function of soil community: a metagenomic and metagenetic approach. Sci. Rep. 7, Article number: 2260.

Cremona, M. V., Ferrari, J., López, S. 2011. Las cenizas volcánicas y los suelos de la región. Revista Presencia 57, 8-11.

Díaz, P. E., Aranda, C., Martínez, O., Godoy, R., Gonzales, A., Valenzuela, E. 2017. Characterization of yeast in hapludands soil with biotechnological potential J. Soil Sci. Plant Nutr. 17, 948-965.

Dighton, F., White, J. F., Oudemans, P. 2005. The fungal community: its organization and role in the ecosystem, Third Ed. Taylor \& Francis, USA, 960.

Fernández, N., Marchelli, P., Gherghel, F., Kost, G., Fontenla, S. 2015. Ectomycorrhizal fungal communities in Nothofagus nervosa (raulí): a comparison between domesticated and naturally established specimens in a native forest of Patagonia, Argentina. Fungal Ecol., 18, 36-47.
Fernández, N., Messuti, M.I., Fontenla, S. 2012. Occurrence of arbuscular mycorrhizas and dark septate endophytes in terrestrial ferns from a rainforest in Patagonia, Argentina. J. Basic Microbiol. $52,1-11$.

Fontenla, S., Godoy, R., Rosso, P., Havrylenko, M. 1998. Root associations in Austrocedrus forests and seasonal dynamics of arbuscular mycorrhizas. Mycorrhiza 8, 29-33.

González, M. E., Amoroso, M., Lara, A., Veblen, T. T., Donoso, C., Kitzberger, T., Mundo, I., Promis, A. 2014. Ecología de disturbios y su influencia en los bosques templados de Chile y Argentina. In: C., Donoso, M. E., González, A., Lara (eds). Ecología Forestal. Ediciones Universidad Austral del Chile, Chile, pp: 411-502.

Iordache, V., Gherghel, F., Kothe, E. 2009. Assessing the effect of disturbances on ectomycorrhiza diversity. Int. J. Environ. Res. Public Health 6, 414-432.

Jorquera, M. A., Martínez, O. A., Marileo, L. G., Acuña, J. J., Saggar, S., Mora, M. L. 2014. Effect of nitrogen and phosphorus fertilization on the composition of rhizobacterial communities of two Chilean Andisol pastures. World J. Microbiol. Biotechnol. 30, 99-107.

Jumpponen, A., Egerton-Warburton, L. M. 2005. Mycorrhizal fungi in successional environments: a community assembly model incorporating host plant, environmental, and biotic filters. In: F. Dighton, J. F. White, P. Oudemans (eds). The fungal community: its organization and role in the ecosystem, Third Edition. Taylor \& Francis, USA, pp: 139-168.

Maaß, S., Migliorini, M., Rillig, M. C., Caruso, T. 2014. Disturbance, neutral theory, and patterns of beta diversity in soil communities. Ecol. Evol. 4, 4766-4774. 
Marín, C., Aguilera, P., Cornejo, P., Godoy, R., Oehl, F., Palfner, G., Boy, J. 2016. Arbuscular mycorrhizal assemblages along contrasting Andean forests of Southern Chile. J. Soil Sci. Plant Nutr. 16, 916-929.

Mestre, M. C., Fontenla, S., Rosa, C. A. 2014. Ecology of cultivable yeasts in pristine forests in northern Patagonia (Argentina) influenced by different environmental factors. Can. J. Microbiol. 60, 371-82.

Mestre, M.C., Pastorino, M.J., Aparicio, A.G., Fontenla, S.B. (2017). Natives helping foreigners? The effect of inoculation of poplar with patagonian beneficial microorganisms. J. Soil Sci. Plant Nutr. 17, 1028-1039.

Mestre, M. C., Rosa, C. A., Safar, S. V., Libkind, D., Fontenla, S. B. 2011. Yeast communities associated with the bulk-soil, rhizosphere and ectomycorrhizosphere of a Nothofagus pumilio forest in northwestern Patagonia, Argentina. FEMS Microbiol. Ecol. 78, 531-41.

Muyzer, G., Brinkhoff, T., Nubel, U., Santegoeds, C., Schafer, H., Wawer, C. 2004. Denaturing gradient gel electrophoresis (DGGE) in microbial ecology. In: G. A. Kowalchuk, F. J. de Bruijn, I. M. Head, A. D. L. Akkermans, J. D. van Elsas (eds). Molecular microbial ecology manual. Kluwer Academic Publishers Dordrecht, pp. 743-769.

Muyzer, G., Smalla, K. 1998. Application of denaturing gradient gel electrophoresis (DGGE) and temperature gradient gel electrophoresis (TGGE) in microbial ecology. Antonie van Leeuwenhoek $73,127-141$.

Nara, K., Nakaya, H., Wu, B., Zhou, Z., Hogetsu, T. 2003. Underground primary succession of ectomycorrhizal fungi in a volcanic desert on Mount Fuji. New Phytol. 159, 743-756.
Nara, Y., Hogetsu, T. 2004. Ectomycorrhizal fungi on established shrubs facilitate subsequent seedling establishment of successional plant species. Ecology 85, 1700-1707.

Nouhra, E., Urcelay, C., Longo, S., Tedersoo, L. 2013. Ectomycorrhizal fungal communities associated to Nothofagus species in Northern Patagonia. Mycorrhiza 23, 487-496.

Rai, M., Varma, A. 2011. Diversity and biotechnology of ectomycorrhizae. Springer-Verlag, Berlin, $459 \mathrm{p}$.

Shade, A., Peter, H., Allison, S. D., Baho, D. L., Berga, M., Bürgmann, H., Huber, D. H., Langenheder, S., Lennon, J. T., Martiny, J. B., Matulich, K. L., Schmidt, T. M., Handelsman J. 2012. Fundamentals of Microbial Community Resistance and Resilience. Front. Microbiol. 3, 417.

Sun, H., Santalahti, M., Pumpanen, J., Köster, K., Berninger, F., Raffaello, T., Jumpponen, A., Asiegbu, F., Heinonsalo, J. 2015. Fungal community shifts in structure and function across a boreal forest fire chronosequence. Appl Environ Microbiol. 81, 7869-7880.

Swanson, F. J., Jones, J., Crisafulli C., González M. E., Lara, A. 2016. Puyehue-Cordón Caulle eruption of 2011: tephra fall and initial forest responses in the Chilean Andes. Bosque 37, 85-96.

Swanson, F. J., Major, J. J. 2005. Physical environments, events, and geological-ecological interactions at Mount St. Helens. In: V. H. Dale, C. M. Swanson, C. M. Crisafulli (eds). Ecological responses to the 1980 eruption of Mt. St. Helens. Springer-Verlag, USA, pp: 27-44.

Tedersoo, L., Gates, G., Dunk, C.W., Lebel, T., May, T.W., Kõljalg, U., Jairus, T. 2009. Establishment of ectomycorrhizal fungal community on isolated Nothofagus cunninghamii seedlings regenerating on dead wood in Australian wet temperate forests: does fruitbody type matter? Mycorrhiza 19, 403-416. 
Valášková, V., Baldrian, P. 2009. Denaturing gradient gel electrophoresis as a fingerprinting method for the analysis of soil microbial communities. Plant Soil Environ. 55, 413-423.

Wagg, C., Jansa, J., Schmid, B., van der Heijden, M. G. 2011. Belowground biodiversity effects of plant symbionts support aboveground productivity. Ecol Lett. 14: 1001-1009.

White, T. J., Bruns, T., Lee, S., Taylor, J. 1990. Amplification and direct sequencing of fungal ribosomal RNA genes for phylogenetics. In: Innis, M. A., Gelfand, D. H., Sninsky, J. J., White, T.J. (eds). PCR Protocols: a guide to methods and applications. Academic Press, USA, pp: 315-322.
Yamanaka, T., Okabe, H. 2006. Distribution of Frankia, ectomycorrhizal fungi, and bacteria in soil after the eruption of Miyake-Jima (Izu Islands, Japan) in 2000. J. For. Res. 11, 21-26.

Yang, G., Cha Joo, Y., Shibuya, M., Yajima, T., Takahashi, K. 1998. The occurrence and diversity of ectomycorrhizas of Larix kaempferi seedlings on a volcanic mountain in Japan. Mycol. Res. 102, 1503-1508. 